\title{
Traumatismo abdominal cerrado
}

\section{Miriam Alcaide Lucena, Ana Patricia Martínez Domínguez, Carlos Garde Lecumberri, Estefanía García Fernández, Benito Mirón Pozo}

Servicio de Cirugia General y Aparato Digestivo, Hospital Universitario San Cecilio. Granada, España.

Acta Gastroenterol Latinoam 2020;50(1):7

Recibido: 05/12/2018 / Aceptado: 24/01/2019 / Publicado online: 23/03/2020 / https://doi.org/10.52787/ydgf7056

Presentamos el caso de un paciente que sufre un traumatismo abdominal cerrado por coz de caballo observándose en pruebas de imagen engrosamiento de la pared de la vesícula biliar con contenido hemorrágico como único hallazgo, sin otras lesiones asociadas intraabdominales.

\section{Abreviaturas}

TAC: Tomografía axial computarizada.

\section{Caso clínico}

Paciente de 38 años sin antecedentes personales de interés que acude a Urgencias por traumatismo abdominal cerrado por coz de caballo. A su llegada a nuestro Centro se encuentra estable hemodinamicamente. A la exploración destaca dolor a la palpación en hipocondrio derecho sin signos de irritación peritoneal. Se solicita analítica en la que destaca cifra de hemoglobina de $11,9 \mathrm{~g} / \mathrm{dL}$ y transaminasas levemente elevadas, no constaban analíticas previas.

Ante la estabilidad del paciente se solicita ecografía (Figuras 1 y 2) que se completa con TAC (Figura 3).
Figura 1. Imagen ecográfica dónde visualizamos vesícula biliar con contenido hemorrágico en su interior con dimensiones de $5,4 \times 2,9 \mathrm{~cm}$.

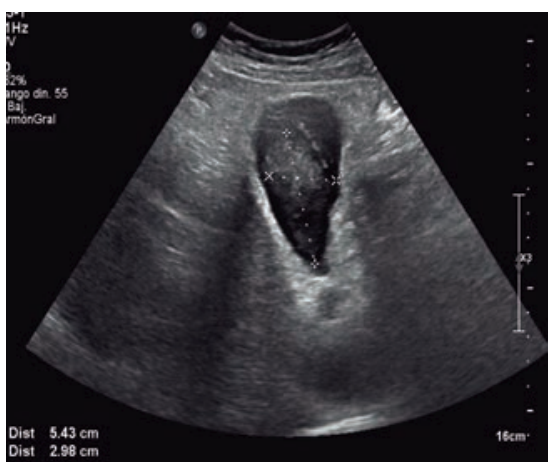

Figura 2. Imagen ecográfica de corte transversal de vesicula biliar con engrosamiento de la pared $(6,9 \mathrm{~mm})$.

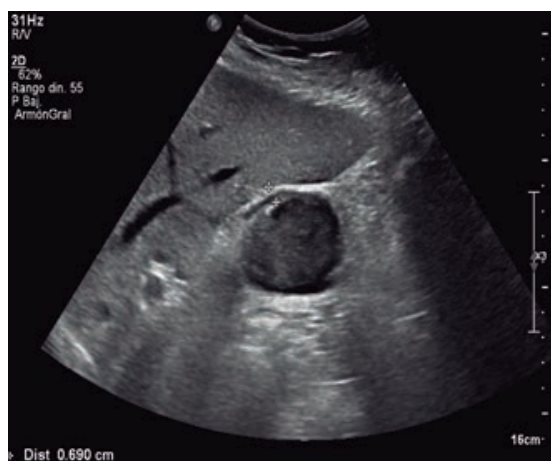

Figura 3. Corte axial de TAC con vesícula de paredes engrosadas y contenido hemorrágico.

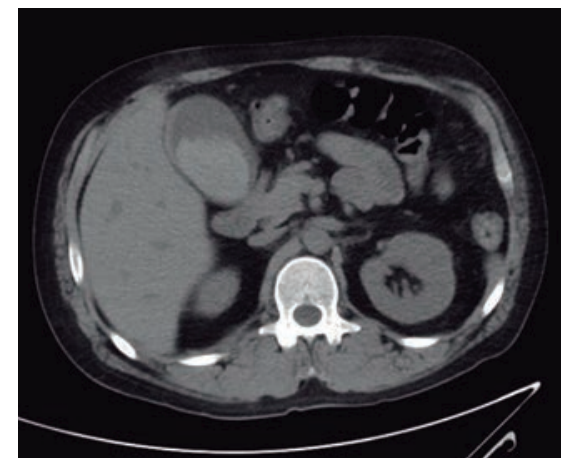

Correspondencia: Miriam Alcaide Lucena

Avda. de la Investigación 2, 18016. Hospital Universitario San Cecilio, Granada, España

Tel.: 958021840

¿Cuál es su diagnóstico?

Correo electrónico: miriam.alcaide.lucena@gmail.com

Resolución del caso en la página 82 


\title{
Solución del caso. Traumatismo abdominal cerrado
}

\author{
Viene de la página 7
}

En la ecografía y TAC abdominal realizados se informa de engrosamiento de la pared vesicular en relación a hematoma mural y contenido hemorrágico intravesicular, con discreto hematoma subcutáneo en pared abdominal, sin líquido libre intraabdominal concluyendo como juicio clínico hemocolecisto traumático.

Ante la estabilidad clínica se decide ingreso en la sala de Cirugía General para tratamiento conservador, analgesia intravenosa y actitud expectante. El paciente evoluciona de forma favorable, con mejoría clínica, analítica y en prueba de imagen, siendo dado de alta a los 7 días con revisiones en consulta sin observarse eventos a destacar.

El término hemocolecisto fue introducido por primera vez en 1961 por Fitzpatrick. Pocos casos han sido descritos en la literatura desde entonces, ya que se trata de un hallazgo poco frecuente y difícil de sospechar. Su etiología es diversa, asociándose a diversas etiologías como neoplasisas biliares, colecistitis, aneurisma de la arteria cística, hemobilia, coagulopatías, manipulación iatrogénica, isquemia y traumatismos abdominales. ${ }^{1,2}$ Por esta última causa, los casos descritos son aún más escasos, y se deben normalmente a grandes politraumatismos, o traumatismos abiertos. Esta baja frecuencia se debe a la ubicación profunda de la vesícula en el abdomen, estando protegida por el hígado y la parrilla costal, aunque puede haber vesículas de localización más anteroinferior con mayor exposición.

El tratamiento puede ir desde la simple observación a la colecistectomía, según la situación hemodinámica del paciente, las lesiones asociadas y su evolución clínica. ${ }^{3}$ Los hemocolecistos producidos por un traumatismo o por alteraciones de la coagulación pueden ser tratados de modo conservador siempre que el paciente se encuentre hemodinámicamente estable, tenga una mejoría clínica y no presente signos de resangrado. ${ }^{4,5}$

Concluimos que nos encontramos ante una rara entidad a tener en cuenta en el diagnóstico diferencial en los traumatismos abdominales que cursen con dolor abdominal en hipocondrio derecho, sobre todo si se trata de pacientes anticoagulados.

Conflicto de intereses. Los autores declaran no tener ningún conflicto de intereses.

\section{Aviso de derechos de autor}

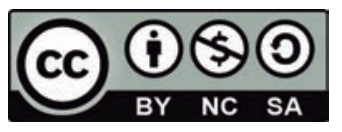

(C) 2021 Acta Gastroenterológica Latinoamericana. Este es un artículo de acceso abierto publicado bajo los términos de la Licencia Creative Commons Attribution (CC BY-NC-SA 4.0), la cual permite el uso, la distribución $y$ la reproducción de forma no comercial, siempre que se cite al autor y la fuente original.

Cite este artículo como: Lucena MA, Martínez Dominguez AP, Lecumberri CG y col. Traumatismo abdominal cerrado. Acta Gastroenterol Latinoam. 2020;50(1):7, 82. https://doi.org/10.52787/ydgf7056

\section{Referencias}

1. Blouhos K, Boulas K, Tselios D, Hatzigeorgiadis A. Spontaneous Hemocholecyst in an End-Stage Renal Failure Patient on Low Molecular Weight Heparin Hemodialysis. Case Reports in Surgery 2012; 1-4.

2. Shin KY, Heo J, Kim JY, Lee SJ, Jang SY, Park SY, Jung MK, Cho CM, Tak WY, Kweon YO. A case of hemocholecyst associated with hemobilia following radiofrequency ablation therapy for hepatocellular carcinoma. Korean J Hepatol 2011; 17: 148-151.

3. Barbon E, Martínez A, Alexandre E, Del Casar J, Díez M. Treatment of a Hemocholecyst. Cir Esp (English Edition) 2014; 92: 293-295.

4. Ramia JM, Puga R, Alonso MA, Quiñones JE, García-Parreño J. Hemocolecisto como complicación del tratamiento anticoagulante y antiplaquetario. Cir Esp 2011; 5: 322-332.

5. Fan Y, Wu S-D, Kong J. Obstructive jaundice and melena caused by hemocholecyst: A case report. World J Gastroenterol 2013; 19: 2126-2128. 